\title{
Self-expanding transcatheter aortic valve replacement using alternative access sites in symptomatic patients with severe aortic stenosis deemed extreme risk of surgery
}

\author{
Michael J. Reardon, MD, ${ }^{\mathrm{a}}$ David H. Adams, MD, ${ }^{\mathrm{b}}$ Joseph S. Coselli, MD, ${ }^{\mathrm{c}}$ G. Michael Deeb, MD, ${ }^{\mathrm{d}}$ \\ Neal S. Kleiman, MD, ${ }^{\mathrm{a}}$ Stan Chetcuti, MD, ${ }^{\mathrm{d}}$ Steven J. Yakubov, MD, ${ }^{\mathrm{e}}$ David Heimansohn, MD ${ }^{\mathrm{f}}$ \\ James Hermiller, Jr, MD, ${ }^{\mathrm{f}}$ G. Chad Hughes, MD, ${ }^{\mathrm{g}}$ J. Kevin Harrison, MD, ${ }^{\mathrm{g}}$ Kamal Khabbaz, MD, \\ Peter Tadros, MD, ${ }^{i}$ George L. Zorn III, MD, ${ }^{i}$ William Merhi, MD ${ }^{j}$ John Heiser, MD, ${ }^{j}$ \\ George Petrossian, MD, ${ }^{\mathrm{k}}$ Newell Robinson, MD, ${ }^{\mathrm{k}}$ Brijeshwar Maini, MD, ${ }^{1}$ Mubashir Mumtaz, MD, \\ Joon Sup Lee, MD, ${ }^{\mathrm{m}}$ Thomas G. Gleason, MD,${ }^{\mathrm{m}}$ Jon Resar, MD, ${ }^{\mathrm{n}}$ John Conte, MD, ${ }^{\mathrm{n}}$ Daniel Watson, MD, \\ Sharla Chenoweth, MS, ${ }^{\circ}$ and Jeffrey J. Popma, MD, ${ }^{\text {h }}$ for the CoreValve US Clinical Investigators
}

Objectives: The CoreValve Extreme Risk US Pivotal Trial enrolled patients with symptomatic severe aortic stenosis deemed unsuitable for surgical aortic valve replacement. Implants were attempted using transfemoral access $(n=489)$ or an alternative access $(n=150)$. In present analysis, we sought to examine the safety and efficacy of CoreValve transcatheter aortic valve replacement using alternative access.

Methods: The present study included 150 patients with prohibitive iliofemoral anatomy who were treated with the CoreValve transcatheter heart valve delivered by way of the subclavian artery $(n=70)$ or a direct aortic approach $(\mathrm{n}=80)$. The echocardiograms were read by an independent core laboratory. The primary endpoint was all-cause mortality or major stroke at 12 months.

Results: The preoperative aortic valve area was $0.72 \pm 0.27 \mathrm{~cm}^{2}$ and mean aortic valve gradient was $49.5 \pm 17.0 \mathrm{~mm}$ $\mathrm{Hg}$. After the transcatheter aortic valve replacement, the effective aortic valve area was $1.82 \pm 0.64 \mathrm{~cm}^{2}$ at 1 month and $1.85 \pm 0.51 \mathrm{~cm}^{2}$ at 12 months. The mean aortic valve gradient was $9.7 \pm 5.8 \mathrm{~mm} \mathrm{Hg}$ at 30 days and $9.5 \pm 5.7 \mathrm{~mm}$ $\mathrm{Hg}$ at 12 months. The death or major stroke rate was $15.3 \%$ at 30 days and $39.4 \%$ at 12 months. The individual rate of all-cause mortality and major stroke was $11.3 \%$ and $7.5 \%$ at 30 days and $36.0 \%$ and $9.1 \%$ at 12 months.

Conclusions: These data demonstrate that the CoreValve transcatheter heart valve delivered by an alternative access provides a suitable alternative for treatment of extreme risk patients with symptomatic severe aortic stenosis, who have prohibitive iliofemoral anatomy and no surgical options. (J Thorac Cardiovasc Surg 2014;148:2869-76)

\section{Supplemental material is available online.}

From the Houston-Methodist-Debakey Heart and Vascular Center, ${ }^{\mathrm{a}}$ Houston, Tex; Mount Sinai Medical Center, ${ }^{\mathrm{b}}$ New York, NY; Texas Heart Institute, ${ }^{\mathrm{c}}$ St Luke's Medical Center, Houston, Tex; University of Michigan Medical Center, ${ }^{\mathrm{d}}$ Ann Arbor, Mich; Riverside Methodist Hospital, ${ }^{\mathrm{e}}$ Columbus, Ohio; St Vincent's Medical Center, ${ }^{\mathrm{f}}$ Indianapolis, Ind; Duke University Medical Center, ${ }^{\mathrm{g}}$ Durham, NC; Beth Israel Deaconess Medical Center, ${ }^{\text {h }}$ Boston, Mass; University of Kansas Hospital, ${ }^{\mathrm{i}}$ Kansas City, Kan; Spectrum Health Hospitals, ${ }^{\mathrm{j}}$ Grand Rapids, Mich; St Francis Hospital, ${ }^{\mathrm{k}}$ Roslyn, NY; Pinnacle Health, ${ }^{1}$ Harrisburg, Pa; University of Pittsburgh Medical Center, ${ }^{\mathrm{m}}$ Pittsburgh, Pa; Johns Hopkins University Hospital, ${ }^{\mathrm{n}}$ Baltimore, Md; and Medtronic, Inc, ${ }^{\circ}$ Minneapolis, Minn.

Disclosures: Michael J. Reardon reports consulting fees from Medtronic. Joseph S. Coselli reports consulting fees for Medtronic and St Jude Medical, and grant support from Medtronic and Edwards Lifesciences. James Hermiller reports consulting fees from Medtronic, Abbott, and St Jude Medical. G. Chad Hughes reports consulting fees for Medtronic and W.L. Gore and lecture fees from Medtronic, W. L. Gore, and Vascutek. Brijeshwar Maini reports consulting fees for and lecture fees from St Jude Medical, Medtronic, and Abbott Vascular. Jon Resar reports grant support from Medtronic and Abbott Vascular. Sharla Chenoweth reports equity ownership in Medtronic. David Heimansohn reports lecture fees from Edwards Lifesciences. Steven J. Yakubov reports consulting fees from Boston Scientific
Transcatheter aortic valve replacement (TAVR) is an accepted therapy in patients poorly suited for surgical aortic valve replacement (SAVR). ${ }^{1-3}$ Although most TAVR procedures are performed using the transfemoral approach, ${ }^{1,4}$ some

and Medtronic. John Conte reports lecture fees from Medtronic. George L. Zorn III reports consulting fees from Medtronic and Edwards. Stan Chetcuti reports consulting fees from Medtronic and Edwards. Peter Tadros reports consulting and lecture fees from Medtronic, Edwards, and St Jude Medical. Jeffrey J. Popma reports consulting fees for Boston Scientific, Covidien, and Abbott Vascular; lecture fees from Boston Scientific; and grant support from Medtronic. Newell Robinson reports consulting fees from Medtronic. All other authors have nothing to disclose with regard to commercial support.

Read at the 94th Annual Meeting of The American Association for Thoracic Surgery, Toronto, Ontario, Canada, April 26-30, 2014.

A complete listing of the investigators, institutions, and research organizations participating in the CoreValve Extreme Risk US Pivotal Trial are listed in Table E1.

Received for publication April 9, 2014; revisions received June 25, 2014; accepted for publication July 5, 2014; available ahead of print Aug 22, 2014.

Address for reprints: Michael J. Reardon, MD, Methodist-Debakey Heart and Vascular Center, 6550 Fannin St, Suite 1401, Houston, TX 77030 (E-mail: mreardon@houstonmethodist.org).

$0022-5223 / \$ 36.00$

Copyright $(C) 2014$ by The American Association for Thoracic Surgery

http://dx.doi.org/10.1016/j.jtcvs.2014.07.020 


\section{Abbreviations and Acronyms \\ NYHA $=$ New York Heart Association \\ PARTNER $=$ Placement of Aortic Transcatheter Valve (trial) \\ SAVR $=$ surgical aortic valve replacement \\ STS $\quad$ Society of Thoracic Surgeons \\ STS-PROM $=$ Society of Thoracic Surgeons- Predicted Risk of Mortality \\ TAVR $=$ transcatheter aortic valve replacement \\ THV $=$ transcatheter heart valve}

patients have anatomy unsuitable for placement of a large femoral sheath.

In such patients, alternative access with the balloonexpandable SAPIEN (Edwards Life Sciences, Irvine, Calif) transcatheter heart valve (THV) has been primarily performed using a transapical approach. ${ }^{2}$ This technique was not allowed in the Placement of Aortic Transcatheter Valve (PARTNER) B inoperable trial but was used in the PARTNER A trial in patients deemed at high risk of SAVR.

In patients with prohibitive iliofemoral vessels, the CoreValve self-expanding THV (Medtronic, Inc, Minneapolis, Minn) has been used with alternative access sites, including the subclavian artery $^{5-7}$ and a direct aortic approach with a medial partial sternotomy or right thoracotomy. ${ }^{8-10}$ The CoreValve Extreme Risk US Pivotal Trial evaluated patients deemed to have a prohibitive risk for surgery and treated with this self-expanding THV using the transfemoral access. A separate arm of the study was designed for patients deemed unsuitable for iliofemoral access and requiring alternative access procedures. Our objective was to evaluate the clinical safety and efficacy of self-expanding TAVR in patients at extreme risk for SAVR in whom alternative access sites were used owing to preclusive iliofemoral anatomy.

\section{METHODS \\ Patient Selection}

The patient selection criteria for the CoreValve Extreme Risk US Pivotal Trial have been previously described in detail. ${ }^{4}$ In brief, patients with severe aortic stenosis and symptoms related to aortic valve disease were eligible for the study. Severe aortic stenosis was defined as an aortic valve area of $\leq 0.8 \mathrm{~cm}^{2}$ or an aortic valve index of $\leq 0.5 \mathrm{~cm}^{2} / \mathrm{m}^{2}$ and either a mean aortic valve gradient $>40 \mathrm{~mm} \mathrm{Hg}$ or a peak aortic valve velocity $>4.0$ $\mathrm{m} / \mathrm{s}$. Patients were considered at extreme risk if 2 cardiac surgeons and 1 interventional cardiologist at the clinical site estimated a $\geq 50 \%$ risk of mortality or irreversible morbidity at 30 days with SAVR. This risk was confirmed by 2 cardiac surgeons and 1 interventional cardiologist on a National Screening Committee.

The anatomic exclusion criteria included an aortic annular diameter $<18 \mathrm{~mm}$ or $>29 \mathrm{~mm}$, moderate to severe mitral stenosis or severe mitral regurgitation, or a dilated ascending aorta. ${ }^{4}$ Computed tomographic angiography of the thoracic and abdominal aorta and common and external iliac and femoral arteries was performed to determine the vessel caliber, presence of calcification, and tortuosity. Patients with permissive femoral and iliac arteries were enrolled in the CoreValve Extreme Risk US Pivotal Trial Iliofemoral Arm. In the event that iliofemoral access was not suitable for placement of an $18 \mathrm{~F}$ sheath, the patients were considered for alternative access.

\section{Study Device}

The CoreValve System consists of 3 components: the THV, delivery catheter system, and compression loading system. The THV comprises a self-expanding nitinol frame that supports a trileaflet porcine pericardial valve. The valves available in the present report included those with 23-, 26-, 29-, and 31-mm diameters, treating patients with an annulus range from 18 to $29 \mathrm{~mm}$. The inflow portion of the frame is designed to conform to the annulus and to stabilize the frame at the annular location. The lowest $12 \mathrm{~mm}$ of the frame contains a porcine pericardial skirt to seal the annulus. The valve is located in a supra-annular position at the waist (constrained portion) of the valve frame. The outflow portion of the valve frame is constructed to support the valve commissures and orient the frame to facilitate laminar flow (Figure E1). All valve sizes are delivered using an $18 \mathrm{~F}$ catheter delivery system. The valve is deployed without rapid pacing and is partially repositionable until annular contact with the THV has been made.

\section{Study Design}

The CoreValve Extreme Risk US Pivotal Trial was a prospective, multicenter, controlled, nonrandomized, single-arm clinical study performed at 41 clinical sites in the United States (Table E1). The responsible institutional review boards approved the study protocol, and all patients provided written informed consent. The trial was conducted in accordance with the International Conference on Harmonization, Good Clinical Practice Guidelines, and the Declaration of Helsinki (ClinicalTrials.gov identifier, NCT01240902).

This study was designed and funded by the study sponsor (Medtronic, Inc). The study sponsor was responsible for the selection of the clinical sites, monitoring the data, management of the case report forms, and statistical analyses. An independent Clinical Events Committee (Table E2) adjudicated all major adverse clinical events. The Data and Safety Monitoring Board was responsible for study oversight. The CoreValve US Steering Committee reviewed the primary report and made the decision to submit it for publication.

\section{Subclavian Access}

An open surgical approach was used to isolate the subclavian artery, and an $18 \mathrm{~F}$ sheath was advanced to the aorta over a stiff 0.035 -in. guidewire positioned in the left ventricle.

\section{Direct Aortic Approach}

A direct aortic approach was used with either a median hemisternotomy or right thoracotomy between the first and second ribs. The $18 \mathrm{~F}$ sheath was advanced into the aorta over a stiff 0.035 -in. guidewire positioned in the left ventricle. The technical details of the subclavian and direct aortic implantation approaches have been previously published. ${ }^{11}$

\section{Procedural Details}

The size of the selected bioprothesis was determined from the pre-enrollment computed tomographic angiogram. Aspirin, 81 to 325 $\mathrm{mg}$, was recommended before the procedure. After general anesthesia was induced, anticoagulation with intravenous heparin or bivalirudin was given to achieve an activated clotting time of $\geq 250$ seconds. Through an $18 \mathrm{~F}$ sheath, aortic valvuloplasty was performed with rapid ventricular pacing. The self-expanding THV was then advanced across the aortic valve. Contrast injections were performed through a pigtail catheter 
positioned at the base of the noncoronary sinus to guide positioning of the inflow portion of the frame 2 to $6 \mathrm{~mm}$ inferior to the noncoronary basal annulus. After valve deployment, the delivery catheter was removed, and valve performance was evaluated using echocardiography, aortography, and hemodynamic measurements. Dual antiplatelet therapy with aspirin, $81 \mathrm{mg}$ daily, and clopidogrel, $75 \mathrm{mg}$ daily, were recommended for 3 months after the procedure. In the event that warfarin was indicated for other reasons, aspirin, $\geq 81 \mathrm{mg}$ daily, was also recommended.

\section{Analysis Populations}

The intended treatment population included all patients accepted by the Screening Committee and who were then enrolled or treated through an alternative access in the study by the clinical sites in the Alternative Access Arm. A detailed assessment of the patient baseline comorbidities was performed using the Society of Thoracic Surgeons (STS) Predicted Risk of Mortality (STS-PROM), ${ }^{12}$ logistic EuroSCORE, ${ }^{12}$ and Charlson comorbidity index. ${ }^{13}$ Frailty markers included a 5 -m gait speed test ${ }^{14}$ and grip strength testing. ${ }^{15}$ Disability was assessed using Katz Activities of Daily Living ${ }^{16}$ and a mini-mental status examination for dementia. The intended treatment population included all patients accepted by the Screening Committee and who were then enrolled or treated through an alternative access in the study in the Alternative Access Arm.

\section{Study Endpoints}

The primary endpoint was the rate of all-cause mortality or major stroke at 12 months after the procedure in the attempted implant population. Major and minor stroke were defined using the Valve Academic Research Consortium-1 criteria. ${ }^{17}$ The criteria for major adverse cardiovascular and cerebral events included all-cause death, myocardial infarction, all stroke events, and reintervention to alter, adjust, or replace a previously implanted valve. Symptom status was assessed using the New York Heart Association (NYHA) classification system. Serial echocardiograms were collected at screening, after the procedure (within 24-48 hours), at hospital discharge, and 1, 6, and 12 months after THV implantation and were interpreted by a Central Laboratory (Mayo Echocardiography Core Laboratory, Rochester, Minn). Prosthetic valve dysfunction and paravalvular regurgitation were determined using Valve Academic Research Consortium- 1 criteria. ${ }^{17}$

\section{Statistical Analysis}

The study had 1 primary objective- to assess the combined all-cause mortality or major stroke rate at 12 months after treatment with the self-expanding THV. Because the outcomes of patients unsuitable for surgery who had prohibitive iliofemoral anatomy had not been previously reported, no objective performance goal was included. The categorical variables were compared using Fisher's exact test or the chi-square test, as appropriate. Continuous variables are presented as the mean \pm standard deviation and were compared using the Student $t$ test. Kaplan-Meier estimates were used to construct the survival curves using all available follow-up data for the time-to-event analysis. All testing used a 2-sided $\alpha$ level of 0.05 . All statistical analyses were performed using Statistical Analysis Systems software, version 9.2 (SAS Institute, Cary, NC).

\section{RESULTS}

From February 2011 to August 2012, 150 patients with prohibitive iliofemoral anatomy were enrolled at 41 centers in the United States and treated with the CoreValve THV (Figure 1). After enrollment completion of the CoreValve Extreme Risk US Pivotal Trial, an additional 339 patients were treated at 45 clinical sites in the Continued Access Study and had $\geq 30$ days of follow-up data available for analysis.

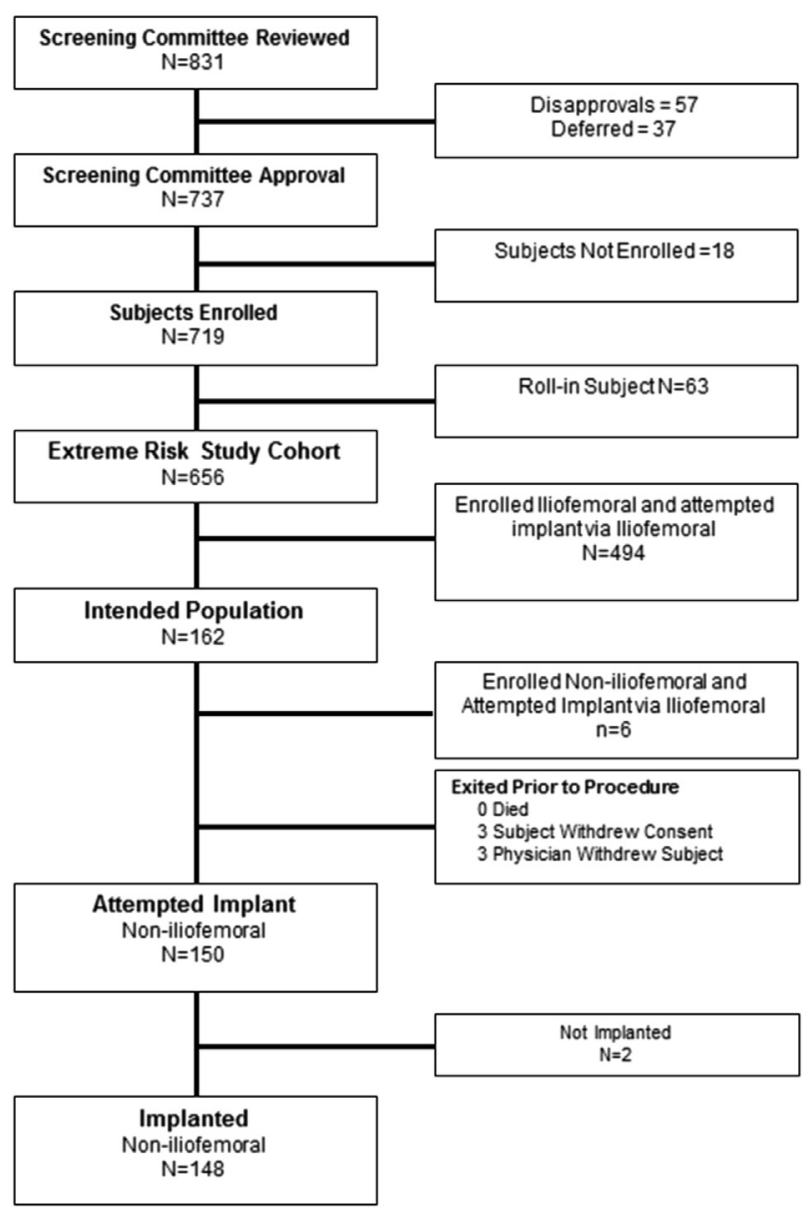

FIGURE 1. Study flow.

\section{Patient Demographics}

The demographics and anatomic contraindications to SAVR for patients in the Pivotal Study and Continued Access Study are reported in Table 1. The patients in the Pivotal Study were elderly (age, $81.3 \pm 7.4$ years), commonly women $(54.7 \%)$, and severely symptomatic (NYHA class III or IV, 92.0\%). The mean Society for Thoracic Surgeons Predicted Risk of Mortality was $10.7 \% \pm 5.7 \%$ and exceeded $15 \%$ in $17.3 \%$ of the patients. A history of atrial fibrillation was present in $48.3 \%$ of patients. No significant differences were found in the standard demographics between the patients enrolled in the Alternative Access Arms of the Pivotal Trial and the Continued Access Study.

Using Society of Thoracic Surgeons criteria, severe lung disease was present in $39.3 \%$ of the patients, and home oxygen therapy was used in $44.0 \%$ of the patients (Table 2). Of the patients, $68.0 \%$ had severe comorbidities when categorized using the Charlson comorbidity index. The average $5-\mathrm{m}$ gait speed was $>6$ seconds for $81.7 \%$ of patients, and the grip strength was less than the age- and sex-matched threshold for $75.0 \%$ of the patients. Objective 
TABLE 1. Patient baseline demographics

\begin{tabular}{|c|c|c|c|}
\hline Demographic data & $\begin{array}{c}\text { Pivotal } \\
(\mathbf{n}=\mathbf{1 5 0})\end{array}$ & $\begin{array}{c}\text { Continued } \\
\text { access } \\
(\mathbf{n}=\mathbf{3 3 9})\end{array}$ & $\begin{array}{c}P \\
\text { value }\end{array}$ \\
\hline Age $(y)$ & $81.3 \pm 7.4$ & $81.8 \pm 8.2$ & .50 \\
\hline Female sex & $82(54.7)$ & $170(50.1)$ & .38 \\
\hline NYHA classification & & & .2 \\
\hline Class II & $12(8.0)$ & $42(12.4)$ & \\
\hline Class III & $98(65.3)$ & $224(66.1)$ & \\
\hline Class IV & $40(26.7)$ & $73(21.5)$ & \\
\hline STS-PROM $(\%)$ & $10.7 \pm 5.7$ & $10.1 \pm 5.6$ & .23 \\
\hline STS-PROM level & & & .25 \\
\hline$<10 \%$ & $75(50.0)$ & $195(57.5)$ & \\
\hline $10 \%-15 \%$ & $49(32.7)$ & $88(26.0)$ & \\
\hline$>15 \%$ & $26(17.3)$ & $56(16.5)$ & \\
\hline Logistic EuroSCORE (\%) & $22.9 \pm 15.9$ & $24.2 \pm 17.2$ & .45 \\
\hline Diabetes mellitus & $51(34.0)$ & $134(39.5)$ & .27 \\
\hline CKD class $4 / 5$ & $21(14.1)$ & $48(14.4)$ & 1.00 \\
\hline History of hypertension & $137(91.3)$ & $308(90.9)$ & 1.00 \\
\hline PVD & $92(61.3)$ & $213(68.1)$ & .15 \\
\hline Previous stroke & $21(14.1)$ & $48(14.2)$ & 1.00 \\
\hline Previous TIA & $16(10.7)$ & $34(10.1)$ & .87 \\
\hline \multicolumn{4}{|l|}{ Cardiac risk factors } \\
\hline Coronary artery disease & $120(80.0)$ & $277(81.7)$ & .71 \\
\hline Previous CABG & $61(40.7)$ & $118(34.8)$ & .22 \\
\hline Previous PCI & $48(32.0)$ & $138(40.7)$ & .07 \\
\hline Previous balloon valvuloplasty & $34(22.7)$ & $68(20.1)$ & .55 \\
\hline Previous pacemaker/defibrillator & $38(25.3)$ & $66(19.5)$ & .15 \\
\hline Previous myocardial infarction & $49(32.7)$ & $104(30.7)$ & .67 \\
\hline $\begin{array}{l}\text { Previous atrial fibrillation/atrial } \\
\text { flutter }\end{array}$ & $72(48.3)$ & $154(45.8)$ & .62 \\
\hline \multicolumn{4}{|l|}{ Unfavorable anatomy } \\
\hline Aorta calcification & & & .67 \\
\hline Severe & $25(16.8)$ & $61(18.0)$ & \\
\hline Porcelain & $12(8.1)$ & $21(6.2)$ & \\
\hline Chest wall deformity & $3(2.0)$ & $7(2.1)$ & 1.00 \\
\hline Hostile mediastinum & $13(8.7)$ & $23(6.8)$ & .4 \\
\hline
\end{tabular}

Data presented as mean \pm standard deviation or $\mathrm{n}(\%)$. Denominator was 489 , unless otherwise indicated. NYHA, New York Heart Association; STS-PROM, Society of Thoracic Surgeons Predicted Risk of Mortality; $C K D$, chronic kidney disease; $P V D$, peripheral vascular disease; $T I A$, transient ischemic attack; $C A B G$, coronary artery bypass grafting; $P C I$, percutaneous coronary intervention; EuroSCORE, European System for Cardiac Operative Risk Evaluation.

measures of disability before the procedure were common (Table 2). The rates of STS severe lung disease $(P<.05)$, home oxygen use $(P=.04)$, and disability using the Katz Activities of Daily Living $(P=.02)$ were less for the patients enrolled in the Continued Access Study than for those enrolled in the Pivotal Trial.

\section{Subclavian Approach}

A total of 70 patients $(46.7 \%)$ underwent THV implantation using the subclavian approach. The mean total procedure time was $67.3 \pm 52.6$ minutes (median, 54.0). The distribution of CoreValve valve sizes was $23 \mathrm{~mm}$ in $0.0 \%, 26 \mathrm{~mm}$ in $42.0 \%, 29 \mathrm{~mm}$ in $53.6 \%$, and $31 \mathrm{~mm}$ in $4.3 \%$. During the procedure, packed red blood cells were
TABLE 2. Comorbidities and frailty

\begin{tabular}{|c|c|c|c|}
\hline Assessment & $\begin{array}{c}\text { Pivotal } \\
(\mathbf{n}=\mathbf{1 5 0})\end{array}$ & $\begin{array}{c}\text { Continued } \\
\text { access } \\
(\mathbf{n}=\mathbf{3 3 9}) \\
\end{array}$ & $\begin{array}{r}P \\
\text { value } \\
\end{array}$ \\
\hline \multicolumn{4}{|l|}{ Comorbidities } \\
\hline STS chronic lung disease & & & $<.05$ \\
\hline None & $42(28.0)$ & $125(36.9)$ & \\
\hline Mild & $27(18.0)$ & $59(17.4)$ & \\
\hline Moderate & $22(14.7)$ & $62(18.3)$ & \\
\hline Severe & $59(39.3)$ & $93(27.4)$ & \\
\hline Home oxygen use & $66(44.0)$ & $116(34.2)$ & .04 \\
\hline $\mathrm{FEV} 1<1000 \mathrm{~mL}$ & $51(34.0)$ & $93(27.4)$ & .12 \\
\hline $\mathrm{DLCO}<50 \%$ & $60(40.0)$ & Not performed & \\
\hline Liver cirrhosis & $1(0.7)$ & $6(1.8)$ & .68 \\
\hline Connective tissue disease & $3(2.0)$ & $14(4.1)$ & .29 \\
\hline Immunosuppressive therapy & $28(18.7)$ & $70(20.6)$ & .71 \\
\hline Charlson comorbidity index & $5.7 \pm 2.2$ & $5.6 \pm 2.3$ & .96 \\
\hline None (score 0 ) & $0(0.0)$ & $0(0.0)$ & .27 \\
\hline Mild (score 1,2) & $9(6.0)$ & $13(3.8)$ & \\
\hline Moderate (score 3, 4) & $39(26.0)$ & $108(32.0)$ & \\
\hline Severe (score 5) & $102(68.0)$ & $217(64.2)$ & \\
\hline \multicolumn{4}{|l|}{ Frailty } \\
\hline Anemia with transfusion & $36(24.7)$ & $83(25.5)$ & .91 \\
\hline $\mathrm{BMI}<21 \mathrm{~kg} / \mathrm{m}^{2}$ & $22(14.7)$ & $55(16.2)$ & .79 \\
\hline Albumin $<3.3 \mathrm{~g} / \mathrm{dL}$ & $25(17.1)$ & $65(19.5)$ & 61 \\
\hline Unplanned weight loss & $21(14.0)$ & $44(13.0)$ & .77 \\
\hline Fall within past 6 mo & $30(20.0)$ & 63 (18.6) & .71 \\
\hline 5-m Gait speed $>6 \mathrm{~s}$ & $98(81.7)$ & $257(89.2)$ & .05 \\
\hline Grip strength less than threshold & $111(75.0)$ & $247(74.4)$ & .91 \\
\hline \multicolumn{4}{|l|}{ Disabilities } \\
\hline Living in assisted living facility & $24(16.0)$ & $38(11.2)$ & .14 \\
\hline \multicolumn{4}{|l|}{ ADLs } \\
\hline Deficit $\geq 1$ ADLs & $42(28.0)$ & $61(18.0)$ & .02 \\
\hline Deficit $\geq 2$ ADLs & $29(19.3)$ & $39(11.5)$ & .02 \\
\hline Deficit $\geq 3$ ADLs & $15(10.0)$ & $27(8.0)$ & .49 \\
\hline \multicolumn{4}{|l|}{ Dementia according to MMSE score } \\
\hline None $(\geq 25)$ & $110(73.8)$ & $250(74.0)$ & .49 \\
\hline Mild (21-24) & $29(19.5)$ & $74(21.9)$ & \\
\hline Moderate (10-20) & $10(6.7)$ & $13(3.8)$ & \\
\hline Severe $(<10)$ & $0(0.0)$ & $1(0.3)$ & \\
\hline
\end{tabular}

$\overline{S T S}$, Society of Thoracic Surgeons; FEVI, forced expiratory volume in 1 second; $D L C O$, diffusion capacity of lung carbon monoxide; $B M I$, body mass index; $A D L s$, activities of daily living; $M M S E$, mini-mental state examination.

administered to $11.4 \%$ of the patients, and $1.4 \%$ received a transfusion of packed red blood cells of $\geq 4$ U. Postimplantation balloon valvuloplasty was performed in $13.0 \%$ of the patients. No events of device migration or embolization occurred. None of the patients required emergency conversion to surgery because of coronary obstruction. None of the patients underwent a concomitant percutaneous coronary intervention. Two valves were implanted in $2.9 \%$ of the patients.

\section{Direct Aortic Approach}

Of the 150 patients, $80(53.3 \%)$ underwent THV implantation using the direct aortic approach. The mean 
TABLE 3. Clinical outcomes at 12 months in the Alternative Access Pivotal Study*

\begin{tabular}{lc}
\hline \multicolumn{1}{c}{ Outcome } & Pivotal $(\mathbf{n}=\mathbf{1 5 0})$ \\
\hline Death from any cause or major stroke & $59(39.4)$ \\
Death & \\
$\quad$ From any cause & $54(36.0)$ \\
Cardiovascular & $42(28.8)$ \\
Stroke & $18(13.0)$ \\
Major & $13(9.1)$ \\
Minor & $6(4.7)$ \\
TIA & $3(2.3)$ \\
MACCE & $62(41.4)$ \\
Myocardial infarction & $3(2.1)$ \\
$\quad$ Periprocedural & $2(1.3)$ \\
$\quad$ Spontaneous & $1(0.7)$ \\
Reintervention & $1(1.0)$ \\
Major or life-threatening bleeding & $96(65.1)$ \\
Life-threatening or disabling & $43(29.4)$ \\
$\quad$ Major & $60(41.9)$ \\
Major vascular complications & $14(9.5)$ \\
Acute kidney injury & $21(14.2)$ \\
Permanent pacemaker placement $\dagger$ & $30(21.5)$ \\
Cardiogenic shock & $9(6.0)$ \\
Cardiac perforation & $2(1.3)$ \\
Device migration & $0(0.0)$ \\
Device embolization & $0(0.0)$ \\
\hline Data presented as n (\%). TIA, Transient ischemic attack; MACCE, major adverse \\
cardiovascular and cerebrovascular events. *All percentages & are Kaplan-Meier \\
estimates at the specific point and thus do not equal the number of patients divided \\
by the total number in the study group. $\dagger$ Patients with pacemaker or implantable \\
cardioverter defibrillator at baseline included. \\
\end{tabular}

total procedure time was $54.6 \pm 39.9$ minutes (median, 40.5). The distribution of the CoreValve valve sizes was $23 \mathrm{~mm}$ in $11.4 \%, 26 \mathrm{~mm}$ in $40.5 \%, 29 \mathrm{~mm}$ in $45.6 \%$, and $31 \mathrm{~mm}$ in $2.5 \%$. During the procedure, packed red blood cells were administered to $35.0 \%$ of the patients, and $3.8 \%$ received a transfusion of packed red blood cells of $\geq 4 \mathrm{U}$. Postimplantation balloon valvuloplasty was performed in $13.9 \%$ of the patients. No episodes of device migration or embolization occurred, and no patient required implantation of $>1$ prosthesis. None of the patients developed coronary obstruction requiring emergency surgical bypass surgery. None of the patients underwent a concomitant percutaneous coronary intervention. None of the patients had 2 valves implanted.

\section{Clinical Outcomes}

By 30 days, the primary endpoint of death or major stroke had occurred in 23 patients $(15.3 \%)$. Of the 23 patients, $17(11.3 \%)$ had died and $11(7.5 \%)$ had experienced major stroke (some patients experienced both). The clinical outcomes at 30 days in the Pivotal and Continued Access Studies are listed in Tables E3 and E4. The rates were slightly lower in the Continued Access Study, with death or major stroke in 40 patients $(11.9 \%$;

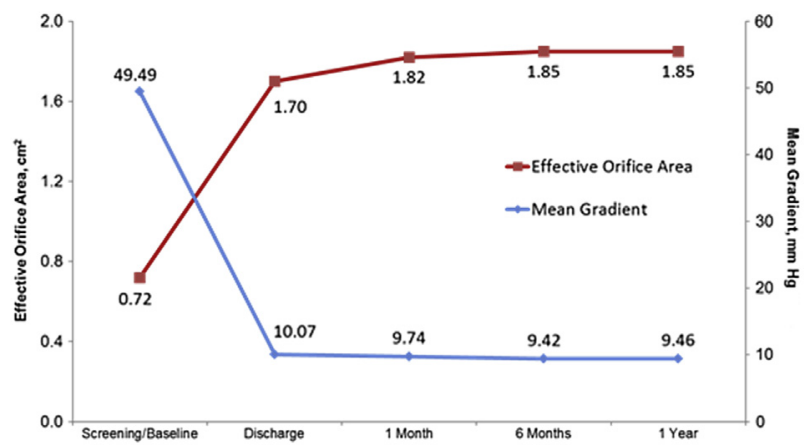

FIGURE 2. Changes in mean aortic valve gradient (blue) and mean effective orifice area (red) during the study period at each follow-up point.

$32[9.5 \%]$ died and $10[3.0 \%]$ experienced major stroke; Table E3).

In the attempted implant population, the primary endpoint of the rate of all-cause mortality or major stroke at 12 months was $39.4 \%$, with an upper $95 \%$ confidence interval of $47.2 \%$ (Figure E2; Table 3). The rate of all-cause mortality at 12 months was $36.0 \%$ and the rate of major stroke at 12 months was $9.1 \%$. Permanent pacemaker implantation was required in 24 patients $(16.4 \%)$ by 30 days and 30 patients $(21.5 \%)$ by 1 year.

The NYHA class mean had improved significantly from baseline to the 12-month follow-up point $(\Delta-1.4 \pm 0.8$; $P<.0001)$. At baseline, most patients $(91.9 \%)$ were in NYHA class III or IV, and at each subsequent followup visit, most patients were in NYHA class I or II (Figure E3).

The echocardiographic data showed a baseline aortic valve area of $0.72 \pm 0.27 \mathrm{~cm}^{2}$ and mean aortic valve gradient of $49.5 \pm 17.0 \mathrm{~mm} \mathrm{Hg}$. After CoreValve TAVR, the effective aortic valve area was $1.82 \pm 0.64 \mathrm{~cm}^{2}$ at 1 month and $1.85 \pm 0.51 \mathrm{~cm}^{2}$ at 12 months. The mean aortic valve gradient was $9.7 \pm 5.8 \mathrm{~mm} \mathrm{Hg}$ at 1 month and $9.5 \pm 5.7 \mathrm{~mm} \mathrm{Hg}$ at 12 months (Figure 2). The degree of paravalvular regurgitation decreased during the followup period, with no regurgitation present in $33.6 \%$ of patients immediately after TAVR and $47.6 \%$ at 1 year. Moderate to severe paravalvular leak was present in 7.0\% at discharge and $2.4 \%$ at 1 year (Figure E4). Paired analysis showed that $85.7 \%$ of patients with moderate or severe paravalvular leak at discharge had improved by 12 months.

\section{DISCUSSION}

We studied alternative access approaches to TAVR using the CoreValve prosthesis to treat severe aortic stenosis in a cohort of patients who had not been studied previously. The patients had been deemed by a local interdisciplinary heart team and a national screening committee to be at extreme risk if undergoing conventional surgery. These decisions were determined using traditional surgical risk 
assessment tools, ${ }^{18}$ such as the STS-PROM ${ }^{12}$ or the logistic EuroSCORE, ${ }^{19}$ and also included subjective assessments that incorporated factors beyond those included in the STS-PROM and EuroSCORE predictive models. Unlike previous populations, the patients in present study $(23.5 \% ; 150$ of the 639 "attempted patients" in the Pivotal Trial) also had peripheral vascular disease severe enough to prohibit placement of an $18 \mathrm{~F}$ femoral sheath. We found that alternative access TAVR with the CoreValve prosthesis in this "no option" population was associated with an acceptable rate of death or major stroke at 12 months $(39.4 \%)$. Implantation of this self-expanding aortic bioprothesis also provided sustained improvement in the aortic valve effective orifice area, a reduction in the mean aortic valve gradient with low rates of aortic insufficiency, and an overall improvement in the NYHA functional class.

\section{Mortality and Major Stroke}

Within the present trial, no prespecified performance goal was identified, because no suitable standard was available to allow estimation of event rates in either treated or untreated patients. However, peripheral vascular disease has been shown in multiple studies to be an independent predictor of mortality in multiple studies of general populations, patients treated medically, and those undergoing surgery, with risk ratios as high as $4.1{ }^{20}$ Thus, mortality in the Extreme Risk Pivotal Trial Alternative Access Arm might be expected to exceed the rates among patients undergoing femoral access TAVR. Within the PARTNER B trial, nonfemoral access was not allowed in patients who had been deemed inoperable. Transapical TAVR was permitted only in patients in the PARTNER A trial who were operable but with high surgical risk. Within the latter trial, the mortality rate 1 year after transapical TAVR was greater than that reported after transfemoral TAVR $(29.0 \%$ vs $22.2 \%){ }^{2}$ The 30 -day mortality rate of $11.3 \%$ in our study was greater than the $5.0 \%$ reported in PARTNER Cohort $\mathrm{B}^{1}$ or the $8.4 \%$ reported in the CoreValve Extreme Risk Trial Iliofemoral $\mathrm{Arm}^{4}$ (both of which required femoral access) but was comparable to the 30-day mortality rate of $10.6 \%$ in the PARTNER A high-risk transapical group ${ }^{21}$ and the 30-day mortality rate of $12.6 \%$ in inoperable patients who were treated with the alternative access and the SAPIEN valve (Lifesciences) in the Transcatheter Valve Therapy Registry. ${ }^{22}$ As expected, the rate of major stroke at 1 year of $9.1 \%$ was similar to the $7.8 \%$ rate reported in PARTNER Cohort B and comparable to the $10.8 \%$ reported in the PARTNER Cohort A transapical group. ${ }^{21}$ Taken in aggregate, these findings suggest strongly that the relatively high event rates were in large part likely to be a consequence of the advanced degree of illness in this patient group.

\section{Aortic Regurgitation}

The results of our study have demonstrated a relatively low rate of moderate or severe paravalvular aortic valve regurgitation $(2.4 \%) 1$ year after CoreValve THV placement. This rate was lower than those previously reported and most likely attributable to precise valve sizing according to the computed tomography assessment of the aortic annular diameter, ${ }^{23,24}$ more precise placement of the bioprosthesis within the aortic annulus using access routes shorter than those for the femoral approach, and the use of postdilatation when significant paravalvular regurgitation was noted during the procedure. The prevalence of moderate aortic regurgitation in our patients decreased during the follow-up period, suggesting ongoing remodeling of the annular-bioprothesis interface with the self-expanding device.

\section{Conduction System Disturbances}

Conduction system disturbances can occur after CoreValve TAVR owing to the mechanical trauma applied by the inflow portion of the valve frame to the membranous septum in the region of the atrioventricular conduction system and left bundle branch. ${ }^{25,26}$ Accordingly, the need for a permanent pacemaker placement after CoreValve THV implantation has been reported to range from $25.8 \%$ to $33.0 \%{ }^{27,28}$ Although placement of a permanent pacemaker does not seem to affect late mortality, ${ }^{29}$ we used "best practices" to reduce the occurrence of conduction disturbances during TAVR, including smaller predilatation balloons, valve sizing using computed tomography guidance, and higher positioning of the CoreValve THV, with avoidance of the conduction system. ${ }^{30}$ In the present study, the rate of permanent pacemaker implantation was $16.4 \%$ at 30 days.

\section{Subclavian Versus Direct Aortic Access}

Subclavian access resulted in lower 30-day all-cause mortality rate than the direct aortic access $(8.6 \%$ vs $13.7 \%)$ but a greater major stroke rate $(8.6 \%$ vs $6.5 \%$, respectively). The conduct of the trial in patients not suitable for femoral access was to move to subclavian access next and then direct aortic access, if subclavian access, was not considered feasible. Direct aortic access requires a more invasive approach than subclavian, and because it is the last approach to consider, these patients might also represent a different risk group.

\section{Continued Access}

We included data from patients enrolled in the Continued Access Study, who had been enrolled between the point of enrollment completion in the Pivotal Study and Food and Drug Administration approval of the CoreValve THV and who had $\geq 30$ days of follow-up data to analyze. The 
traditional patient characteristics were similar to those observed in the Pivotal Trial, but the patients treated in the Continued Access Study had lower rates of disabilities (Table 2). Coupled with a procedural learning curve, this might have contributed to the lower rates of 30-day mortality $(9.5 \%)$ and major stroke $(3.0 \%)$. In the nonrandomized continued access portion of the PARTNER A trial, similar observations included improvement in the transapical TAVR outcomes as site experience increased. ${ }^{21}$

\section{Study Limitations}

Although the present study is the first to describe the outcomes of a new technique in a hitherto unexplored population, it had several limitations. First, because of ethical concerns surrounding the futility of medical treatment for patients with symptomatic severe aortic stenosis, the study was performed without a medically managed control group. The novelty of the present population also made it impossible to determine a virtual event rate for a control group, which would have been required to establish a performance standard, such as was done in the CoreValve Extreme Risk US Pivotal Trial Iliofemoral Arm. Thus, although we consider it a reasonable assumption that treatment of these patients using noniliofemoral access is superior to medical therapy alone, the statement cannot be made with absolute certainty. However, some reassurance can be found in the observation by the PARTNER Cohort A investigators that in a lower risk group of patients, the 1-year outcomes after transapical TAVR were not different than those after surgical AVR. A second limitation was that the number of patients enrolled in the present study was inadequate to permit a reliable comparison between the subclavian and direct aortic approaches to TAVR.

\section{CONCLUSIONS}

The results of the present study have demonstrated that noniliofemoral alternative access for TAVR with the CoreValve prosthesis is technically feasible and associated with acceptable rates of death or major stroke, low rates of moderate or severe aortic insufficiency, and marked improvements in symptomatic status in patients with severe aortic stenosis who are at prohibitive risk of surgical AVR.

\section{References}

1. Leon MB, Smith CR, Mack M, Miller DC, Moses JW, Svensson LG, et al. Transcatheter aortic-valve implantation for aortic stenosis in patients who cannot undergo surgery. N Engl J Med. 2010;363:1597-607.

2. Smith CR, Leon MB, Mack MJ, Miller DC, Moses JW, Svensson LG, et al. Transcatheter versus surgical aortic-valve replacement in high-risk patients. N Engl J Med. 2011;364:2187-98.

3. Adams DH, Popma JJ, Reardon MJ, Yakubov SJ, Coselli JS, Deeb MG, et al. Transcatheter aortic-valve replacement with a self-expanding prosthesis. N Engl J Med. 2014;370:1790-8.
4. Popma JJ, Adams DH, Reardon MJ, Yakubov SJ, Kleiman NS, Heimansohn D, et al. Transcatheter aortic valve replacement using a self-expanding bioprosthesis in patients with severe aortic stenosis at extreme risk for surgery. J Am Coll Cardiol. 2014;63:1972-81.

5. Petronio AS, De Carlo M, Bedogni F, Maisano F, Ettori F, Klugmann S, et al. 2-Year results of CoreValve implantation through the subclavian access: a propensity-matched comparison with the femoral access. J Am Coll Cardiol. 2012;60:502-7.

6. Schafer U, Ho Y, Frerker C, Schewel D, Sanchez-Quintana D, Schofer J, et al. Direct percutaneous access technique for transaxillary transcatheter aortic valve implantation: "the Hamburg Sankt Georg approach." JACC Cardiovasc Interv. 2012;5:477-86.

7. Testa L, Brambilla N, Laudisa ML, De Carlo M, Lanotte S, Latini RA, et al. Right subclavian approach as a feasible alternative for transcatheter aortic valve implantation with the CoreValve ReValving System. EuroIntervention. 2012;8:685-90.

8. Bruschi G, De Marco F, Botta L, Oreglia J, Colombo P, Paino R, et al. Direct transaortic CoreValve implantation through right minithoracotomy in patients with patent coronary grafts. Ann Thorac Surg. 2012;93:1297-9.

9. Bruschi G, de Marco F, Botta L, Cannata A, Oreglia J, Colombo P, et al. Direct aortic access for transcatheter self-expanding aortic bioprosthetic valves implantation. Ann Thorac Surg. 2012;94:497-503.

10. Bruschi G, De Marco F, Botta L, Oreglia J, Colombo P, Colombo T, et al Trans-aortic access for transcatheter aortic valve implantation: single center experience. JACC. 2011;58:B208.

11. Ramlawi B, Bedeir K, Barker C, Lin CH, Kleiman N, Reardon M. Direct aortic and subclavian access for transcatheter aortic valve replacement: decision making and technique. J Thorac Cardiovasc Surg. 2014;148:353-6.

12. O'Brien S, Shahian D, Filardo G, Ferraris V, Haan C, Rich J, et al. The Society of Thoracic Surgeons 2008 cardiac surgery risk models: part 2-isolated valve surgery. Ann Thorac Surg. 2009;88:S23-42.

13. Charlson ME, Pompei P, Ales KL, MacKenzie CR. A new method of classifying prognostic comorbidity in longitudinal studies: development and validation. J Chronic Dis. 1987;40:373-83.

14. Afilalo J, Eisenberg MJ, Morin JF, Bergman H, Monette J, Noiseux N, et al. Gai speed as an incremental predictor of mortality and major morbidity in elderly patients undergoing cardiac surgery. J Am Coll Cardiol. 2010;56:1668-76.

15. Bohannon RW, Bear-Lehman J, Desrosiers J, Massy-Westropp N, Mathiowetz V Average grip strength: a meta-analysis of data obtained with a Jamar dynamometer from individuals 75 years or more of age. J Geriatr Phys Ther. 2007;30:28-30.

16. Katz S, Ford AB, Moskowitz RW, Jackson BA, Jaffe MW. Studies of illness in the aged. The index of ADL: a standardized measure of biological and psychosocial function. JAMA. 1963;185:914-9.

17. Leon MB, Piazza N, Nikolsky E, Blackstone EH, Cutlip DE, Kappetein AP, et al. Standardized endpoint definitions for transcatheter aortic valve implantation clinical trials: a consensus report from the Valve Academic Research Consortium. J Am Coll Cardiol. 2011;57:253-69.

18. Green P, Woglom AE, Genereux P, Daneault B, Paradis JM, Schnell S, et al. The impact of frailty status on survival after transcatheter aortic valve replacement in older adults with severe aortic stenosis: a single-center experience. JACC Cardiovasc Interv. 2012;5:974-81.

19. Roques F, Michel P, Goldstone AR, Nashef SA. The logistic EuroSCORE Eur Heart J. 2003;24:881-2.

20. Golomb BA, Dang TT, Criqui MH. Peripheral arterial disease: morbidity and mortality implications. Circulation. 2006;114:688-99.

21. Dewey TM, Bowers B, Thourani VH, Babaliaros V, Smith CR, Leon MB, et al Transapical aortic valve replacement for severe aortic stenosis: results from the nonrandomized continued access cohort of the PARTNER trial. Ann Thorac Surg. 2013;96:2083-9.

22. Mack MJ, Brennan JM, Brindis R, Carroll J, Edwards F, Grover F, et al Outcomes following transcatheter aortic valve replacement in the United States. JAMA. 2013;310:2069-77.

23. Binder RK, Webb JG, Willson AB, Urena M, Hansson NC, Norgaard BL, et al. The impact of integration of a multidetector computed tomography annulus area sizing algorithm on outcomes of transcatheter aortic valve replacement: a prospective, multicenter, controlled trial. J Am Coll Cardiol. 2013;62:431-8.

24. Jilaihawi H, Kashif M, Fontana G, Furugen A, Shiota T, Friede G, et al Cross-sectional computed tomographic assessment improves accuracy of aortic annular sizing for transcatheter aortic valve replacement and reduces the incidence of paravalvular aortic regurgitation. J Am Coll Cardiol. 2012;59: $1275-86$. 
25. Piazza N, Onuma Y, Jesserun E, Kint PP, Maugenest AM, Anderson RH, et al. Early and persistent intraventricular conduction abnormalities and requirements for pacemaking after percutaneous replacement of the aortic valve. JACC Cardiovasc Interv. 2008;1:310-6.

26. Fraccaro C, Buja G, Tarantini G, Gasparetto V, Leoni L, Razzolini R, et al. Incidence, predictors, and outcome of conduction disorders after transcatheter self-expandable aortic valve implantation. Am J Cardiol. 2011;107:747-54.

27. Erkapic D, De Rosa S, Kelava A, Lehmann R, Fichtlscherer S, Hohnloser SH. Risk for permanent pacemaker after transcatheter aortic valve implantation: a comprehensive analysis of the literature. J Cardiovasc Electrophysiol. 2012;23:391-7.

28. Khawaja MZ, Rajani R, Cook A, Khavandi A, Moynagh A, Chowdhary S, et al. Permanent pacemaker insertion after CoreValve transcatheter aortic valve implantation: incidence and contributing factors (the UK CoreValve Collaborative). Circulation. 2011;123:951-60.

29. Buellesfeld L, Stortecky S, Heg D, Hausen S, Mueller R, Wenaweser P, et al. Impact of permanent pacemaker implantation on clinical outcome among patients undergoing transcatheter aortic valve implantation. J Am Coll Cardiol. 2012;60:493-501.

30. Piazza N, Nuis RJ, Tzikas A, Otten A, Onuma Y, Garcia-Garcia H, et al. Persistent conduction abnormalities and requirements for pacemaking six months after transcatheter aortic valve implantation. EuroIntervention. 2010;6:475-84.

\section{Discussion}

Dr Friedrich M. Mohr (Leipzig, Germany). Dr Reardon, thank you very much for this excellent presentation and also for providing the report in advance, which only had the 150 patients in writing compared with 338 patients right now in your talk, which is, of course, something I could not review in advance.

I will focus on the 150 patients in your report. In this analysis, you report the early and 1-year outcome of 150 patients with severe aortic stenosis and aortoiliac and femoral stenosis. All patients were treated using the transcatheter CoreValve system for aortic valve replacement through an alternative route, which was, in 70 times, the subclavian artery, or in 80 times, the direct aortic approach.

All patients could be treated successfully. In some of the patients, 2 valves were implanted. Perhaps you can expand on that, whether it was 1 patient who received 2 , a valve-in-valve, or 2 patients. A number of 2.9 did not make any sense to me. This is question 1.

By 30 days, the primary endpoint of death and major stroke had occurred in 23 or $15 \%$ of the patients. You further reported that death occurred in 17 patients or $11.3 \%$, and major stroke in 11 or $17.5 \%$. If you sum the data, 11 and 17 , this does not equal 23 . This somehow does not fit together. So, I have a mathematical problem.

The reported stroke rates seem to be greater compared with those from other studies, such as the SAPIEN Aortic Bioprosthesis European Outcome (SOURCE) Registry identified major access complications associated with high 30-day mortality and/or the German Aortic Valve Registry reporting on transapical access implanting other alternative valves compared with the CoreValve. Can you comment on that?
Finally, I congratulate you on the reported results in this high-risk population. Although, a control group is lacking, the published data from the past 10 years has proved the benefit of TAVR versus medical treatment. It would be interesting to randomly compare all alternative routes, including the transapical approach.

Dr Reardon. Thank you, Dr Mohr.

As far as the question about the SOURCE registry and GARY, of course, these are registries with self-reported data. In the CoreValve trial, we already knew that the Food and Drug Administration was keenly interested in stroke; thus, every patient in the CoreValve Pivotal Trial had a National Institutes of Health stroke scale assessment before treatment and a National Institutes of Health stroke scale assessment immediately after treatment. If any changes at all were found, the patient underwent a neurologic evaluation and imaging studies.

Thus, we actually studied the data a lot more than registries have tended to or that the PARTNER trial did because the study of the data was all retrospective. So, it was not surprising if we had a greater incidence of strokes, because if you look harder, you tend to find more.

Additionally, transapical access was not allowed in the nonoperable extreme risk patients in the PARTNER B trial, and most of the patients in the registries you mentioned were high- to intermediate-risk patients. These were not high-risk patients as you stated but extreme risk patients comparable to those in the PARTNER B trial.

I believe the 339 additional patients in the continued access group were included in the report, and I apologize for any confusion. The number of patients who required the use of 2 valves was $2.9 \%$ and included those with a valve-in-valve and those who had had the first valve removed and a second valve placed, ending with only 1 valve in place but 2 valves used.

The question about death or major stroke at 30 days occurring in 23 patients, death as an isolated event in 17 and major stroke as an isolated event in 11 does add up, because some patients experienced both major stroke and death. They were therefore counted individually in each the death and major stroke isolated categories but only once in the death or major stroke group, because this is an "or" statement.

Dr Mohr. Okay.

Dr Reardon. However, there are some differences, and, again, I think, 1 of the differences, when you try to compare our study to registries such as SOURCE or GARY or the France II or UK, is that this was really a single-arm longitudinal study that demands data input. It requires outside monitoring. It requires outside clinical events review. It demands outside core laboratories, and it fits all the criteria of a very strict Food and Drug Administration trial. So it does make it a unique way of looking at this.

Dr Mohr. Thank you. 


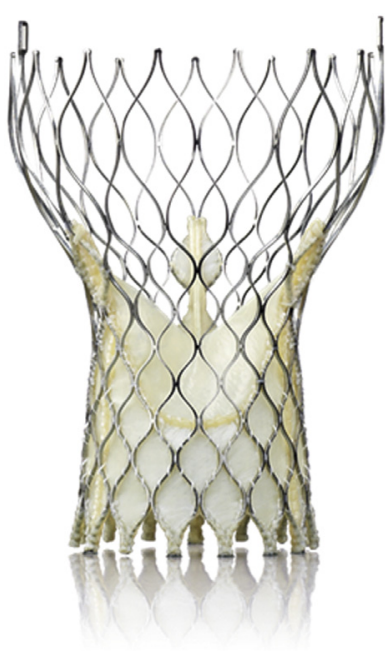

\author{
Outflow \\ Orientation \\ Constrained Portion \\ Valve Function \\ Inflow Portion \\ Sealing
}

FIGURE E1. CoreValve transcatheter heart valve. The self-expanding nitinol frame serves to anchor the transcatheter heart valve at the level of the aortic annulus. The supra-annular trileaflet porcine pericardial valve is hand sewn to the nitinol frame.

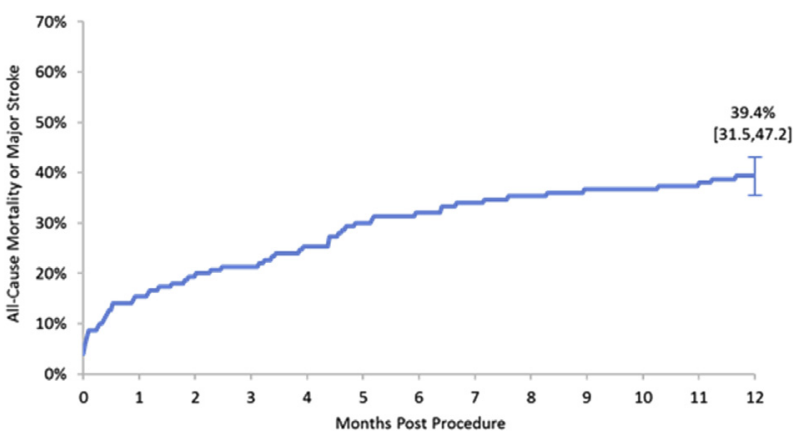

FIGURE E2. Cumulative event curve for all-cause mortality or major stroke. Event rates were calculated using the Kaplan-Meier method. Brackets indicate $95 \%$ confidence intervals.

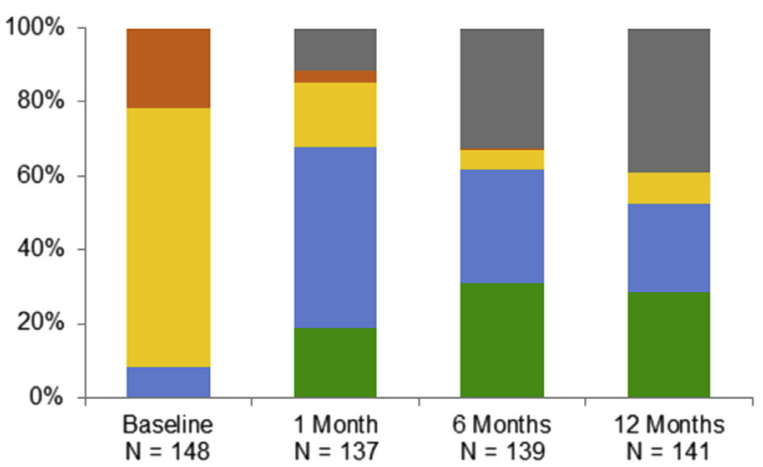

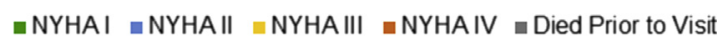

FIGURE E3. New York Heart Association (NYHA) classification during the study period. Symptom status according to New York Heart Association class is shown at baseline and 30 days, 6 months, and 12 months for patients undergoing attempted transcatheter aortic valve replacement.

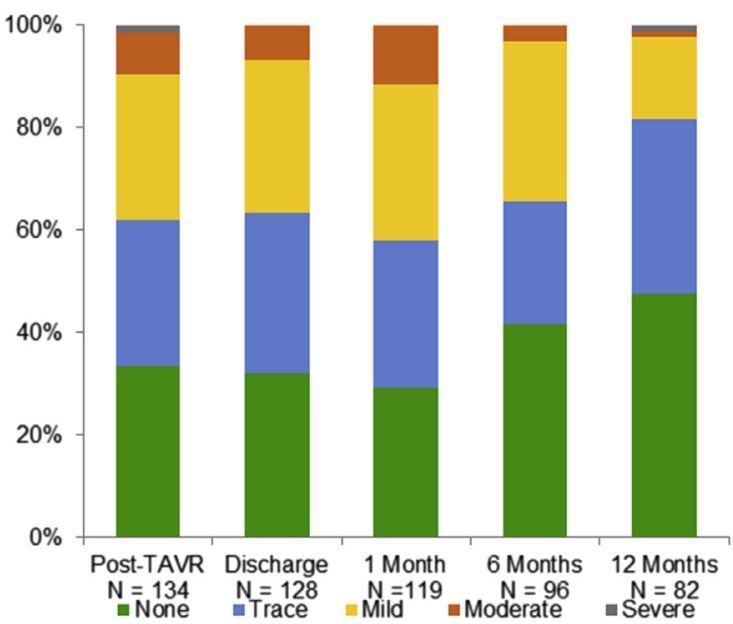

FIGURE E4. Changes in paravalvular regurgitation during the study period. The percentage of patients by degree of paravalvular aortic regurgitation is shown at each follow-up interval. TAVR, Transcatheter aortic valve replacement. 
TABLE E1. Participating investigational sites and personnel

\begin{tabular}{|c|c|}
\hline Center & Location \\
\hline Banner Good Samaritan & Phoenix, Ariz \\
\hline Baylor Heart and Vascular Hospital & Dallas, Tex \\
\hline Beth Israel Deaconess Medical Center & Boston, Mass \\
\hline Cardiovascular Institute of the South & Houma, La \\
\hline Detroit Medical Center Cardiovascular Institute & Detroit, Mich \\
\hline Duke University Medical Center & Durham, NC \\
\hline El Camino Hospital & Mountain View, Calif \\
\hline Fletcher Allen Health Care & Burlington, $\mathrm{Vt}$ \\
\hline Geisinger Medical Center & Danville, $\mathrm{Pa}$ \\
\hline Hartford Hospital & Hartford, Conn \\
\hline $\begin{array}{l}\text { Inova Fairfax Hospital, Inova Heart and Vascular } \\
\text { Institute }\end{array}$ & Falls Church, Va \\
\hline Iowa Heart Center & Des Moines, Iowa \\
\hline Kaiser Permanente Los Angeles Medical Center & Los Angeles, Calif \\
\hline Lenox Hill Hospital & New York, NY \\
\hline Loyola University Medical Center & Maywood, Ill \\
\hline Morristown Memorial Hospital & Morristown, NJ \\
\hline Mount Sinai Medical Center & Miami Beach, Fla \\
\hline New York University/Langone Medical Center & New York, NY \\
\hline North Shore University Hospital & Manhasset, NY \\
\hline Piedmont Heart Institute & Atlanta, Ga \\
\hline Pinnacle Health & Harrisburg, $\mathrm{Pa}$ \\
\hline Providence Sacred Heart Medical Center & Spokane, Wash \\
\hline $\begin{array}{l}\text { Riverside Methodist Hospital/Ohio Health } \\
\text { Research Institute }\end{array}$ & Columbus, Ohio \\
\hline Saint Joseph's Hospital of Atlanta & Atlanta, Ga \\
\hline Spectrum Health Hospitals & Grand Rapids, Mich \\
\hline St Francis Hospital & Roslyn, NY \\
\hline St John Hospital and Medical Center & Detroit, Mich \\
\hline St Luke's Medical Center, Aurora Health Center & Milwaukee, Wis \\
\hline St Vincent Heart Center of Indiana & Indianapolis, Ind \\
\hline $\begin{array}{l}\text { Texas Heart Institute, St Luke's Episcopal } \\
\text { Hospital/Baylor College of Medicine }\end{array}$ & Houston, Tex \\
\hline $\begin{array}{l}\text { Houston-Methodist-Debakey Heart and Vascular } \\
\text { Center/Methodist Hospital }\end{array}$ & Houston, Tex \\
\hline Johns Hopkins University Hospital & Baltimore, Md \\
\hline Mount Sinai Medical Center & New York, NY \\
\hline $\begin{array}{l}\text { Ohio State University Medical Center, } \\
\text { The Richard M. Ross Heart Hospital }\end{array}$ & Columbus, Ohio \\
\hline University Hospitals/Case Medical Center & Cleveland, Ohio \\
\hline University of Kansas Hospital & Kansas City, Kan \\
\hline University of Miami Health System & Miami, Fla \\
\hline University of Michigan Health System & Ann Arbor, Mich \\
\hline University of Pittsburgh Medical Center & Pittsburgh, $\mathrm{Pa}$ \\
\hline $\begin{array}{l}\text { University of Southern California, University } \\
\text { Hospital }\end{array}$ & Los Angeles, Calif \\
\hline Veterans Affairs Palo Alto Health Care System & Palo Alto, Calif \\
\hline Vanderbilt University Medical Center & Nashville, Tenn \\
\hline Wake Forest University Baptist Medical Center & Winston-Salem, NC \\
\hline $\begin{array}{l}\text { Washington Hospital Center, Georgetown } \\
\text { Hospital }\end{array}$ & Washington, DC \\
\hline $\begin{array}{l}\text { Yale New Haven Hospital, Yale University } \\
\text { School of Medicine }\end{array}$ & New Haven, Conn \\
\hline
\end{tabular}


TABLE E2. CoreValve US Pivotal Study organization

Steering committee

Screening committee

Site monitoring

Electronic database

Data management

Biostatistics

Data safety monitoring board

Safety officer

Clinical events committee

Echocardiography core laboratory

ECG core laboratory

Economic and quality of life core laboratory

Global proctors
Jeffrey Popma (co-chair), Beth Israel Deaconess Medical Center, Harvard Medical School, Boston, Mass; Thomas Armitage (co-chair), Structural Heart, Medtronic, Inc, Mounds View, Minn

Cardiac surgeons: David Adams, Mount Sinai Medical Center, New York, NY; John Byrne, Vanderbilt University School of Medicine, Nashville, Tenn; Joseph Coselli, Texas Heart Institute, Houston, Tex; Tom Gleason, University of Pittsburgh Medical Center, Pittsburgh, Pa; G. Michael Deeb, University of Michigan, Ann Arbor, Mich; Michael Reardon, Houston-Methodist-Debakey Heart and Vascular Center, Houston, Tex

Interventional cardiologists: William Anderson, University of Pittsburgh Medical Center, Pittsburgh, Pa James Hermiller, St Vincent Heart Center of Indiana, Indianapolis, Ind; Steven Yakubov, Riverside Methodist Hospital/Ohio Health Research Institute, Columbus, Ohio; Maurice Buchbinder, Veterans Affairs Palo Alto Health Care System, San Diego, Calif

Consultants: Patrick Serruys, Thoraxcenter, Erasmus University, Rotterdam, The Netherlands; Blasé Carabello, Baylor College of Medicine, Houston, Tex

Cardiac surgeons: David H. Adams, Mount Sinai Medical Center, New York, NY; John Byrne, Vanderbilt University, Nashville, Tenn; Thomas G. Gleason, University of Pittsburgh Medical Center, Pittsburgh, $\mathrm{Pa}$; G. Michael Deeb, University of Michigan, Ann Arbor, Mich; Michael Reardon, Houston-MethodistDebakey Heart and Vascular Center, Houston, Tex (chair); John Conte, Johns Hopkins Medical Center, Baltimore, Md

Interventional cardiologists: Steven Yakubov, Riverside Methodist Hospital/Ohio Health Research Institute, Columbus, Ohio; Jeffrey J. Popma, Beth Israel Deaconess Medical Center, Boston, Mass

Global Clinical Operations, Medtronic, Inc, Mounds View, Minn

Oracle Clinical, Oracle Corporation, Redwood Shores, Calif

Global Clinical Operations, Medtronic, Inc, Mounds View, Minn

Structural Heart, Medtronic, Inc, Mounds View, Minn; Harvard Clinical Research Institute, Boston, Mass

David Faxon (chair, IC), Brigham and Women's Hospital, Boston, Mass; William Holman (CS), Birmingham, Ala; John Orav (biostatistics), Brigham and Women's Hospital, Boston, Mass; Scott E. Kasner (neurologist), Hospital of the University of Pennsylvania; John J. Lopex (IC), Loyola University, Maywood, Ill

Tom Vassiliades, Jr, Office of Medical Affairs, Structural Heart, Medtronic, Inc, Mounds View, Minn

Cardiac or vascular surgeons (CS): Ed Gravereaux, Brigham and Women's Hospital, Boston, Mass; Roberto Rodriguez, Caritas St Elizabeth Medical Center, Brighton, Mass; Sanjay Samy, Guthrie Clinic Sayre, $\mathrm{Pa}$

Interventional cardiologists (IC): Cliff Berger, Boston Medical Center, Boston, Mass; Donald Cutlip, Beth Israel Deaconess Medical Center, Boston, Mass; Carey Kimmelstiel, New England Medical Center, Boston, Mass; Sergio Waxman, Lahey Medical Center, Burlington, Mass

Neurologists: John Dashe, New England Medical Center, Boston, Mass; David Thaler, Lahey Medical Center, Burlington, Mass

Heart failure specialist: David DeNofrio, New England Medical Center, Boston, Mass

Jae K. Oh, Mayo Echocardiography Core Laboratory, Rochester, Minn

Peter Zimetbaum, Harvard Clinical Research Institute, Boston, Mass

David Cohen, Mid-America Medical Center, Kansas City, Mo; Matthew Reynolds, Harvard Clinical Research Institute, Boston, Mass

Raoul Bonan, Montreal, Quebec, Canada; Stephen Brecker, St George's Hospital, London, UK; Haim Danenberg, Hadassah Hebrew University, Jerusalem, Israel; Eberhard Grube, Heart Center Siegburg, Germany; Anders Jonsson, Karolinska, Stockholm, Sweden; Iassen Michev, New York, NY; Jean-Claude Laborde, Clinique Pasteur, Toulouse, France

$E C G$, Electrocardiography; $I C$, interventional cardiologist; $C S$, cardiac or vascular surgeon. 
TABLE E3. Clinical outcomes at 30 days*

\begin{tabular}{|c|c|c|c|}
\hline Outcome & $\begin{array}{c}\text { Pivotal } \\
(\mathbf{n}=\mathbf{1 5 0})\end{array}$ & $\begin{array}{c}\text { Continued } \\
\text { access } \\
(\mathbf{n}=\mathbf{3 3 9}) \\
\end{array}$ & $\begin{array}{c}P \\
\text { value } \\
\end{array}$ \\
\hline Death from any cause or major stroke & $23(15.3)$ & $40(11.9)$ & .28 \\
\hline \multicolumn{4}{|l|}{ Death } \\
\hline From any cause & $17(11.3)$ & $32(9.5)$ & .55 \\
\hline Cardiovascular & $17(11.3)$ & $32(9.5)$ & .55 \\
\hline Stroke & $13(8.8)$ & $18(5.4)$ & .16 \\
\hline Major & $11(7.5)$ & $10(3.0)$ & .03 \\
\hline Minor & $3(2.1)$ & $8(2.4)$ & .79 \\
\hline TIA & $2(1.4)$ & $1(0.3)$ & .18 \\
\hline MACCE & $26(17.3)$ & $52(15.4)$ & .60 \\
\hline Myocardial infarction & $3(2.1)$ & $4(1.2)$ & .48 \\
\hline Periprocedural & $2(1.3)$ & $4(1.2)$ & .89 \\
\hline Spontaneous & $1(0.7)$ & $0(0.0)$ & .13 \\
\hline Reintervention & $0(0.0)$ & $2(0.6)$ & .35 \\
\hline Major or life-threatening bleeding & $87(58.3)$ & $184(54.4)$ & .51 \\
\hline Life-threatening or disabling & $36(24.2)$ & $80(23.7)$ & .95 \\
\hline Major & $55(37.1)$ & $110(32.7)$ & .37 \\
\hline Major vascular complications & $13(8.7)$ & $14(4.2)$ & .04 \\
\hline Permanent pacemaker placement $\dagger$ & $24(16.4)$ & $60(18.2)$ & .64 \\
\hline Acute kidney injury & $21(14.2)$ & $48(14.5)$ & .89 \\
\hline Cardiogenic shock & $9(6.0)$ & $21(6.2)$ & .93 \\
\hline Cardiac perforation & $2(1.3)$ & $7(2.1)$ & .58 \\
\hline $\begin{array}{l}\text { TIA, Transient ischemic attack; MAC } \\
\text { cerebrovascular events. *All percentages } \\
\text { the specific point and thus do not equal t } \\
\text { number in the study group. } \dagger \text { Patients wi }\end{array}$ & najor ad & $\mathrm{car}$ & total \\
\hline
\end{tabular}


TABLE E4. Clinical outcomes at 30 days*

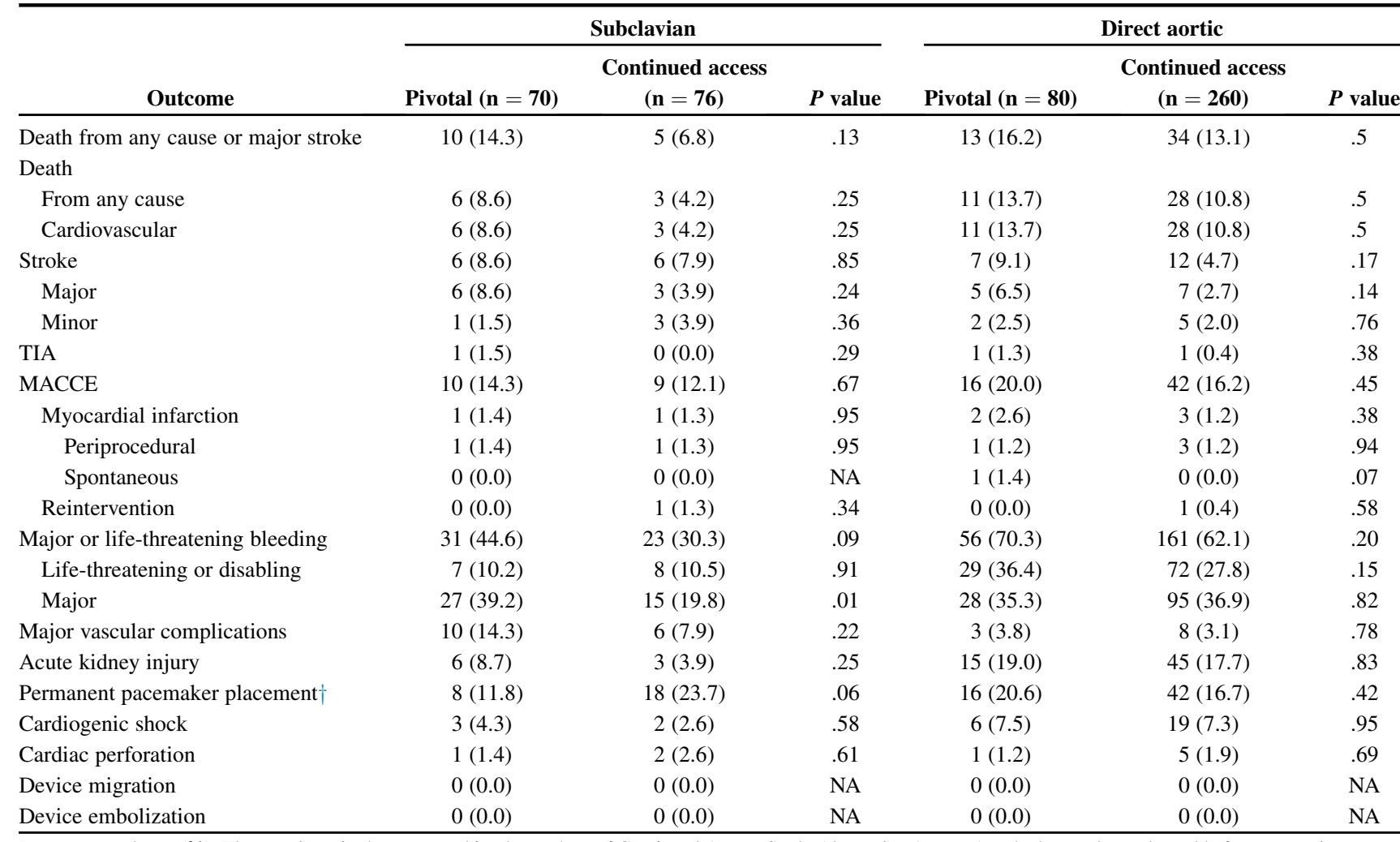

Data presented as n (\%). Three patients in the attempted implant cohort of Continued Access Study Alternative Access Arm had procedures aborted before attempting access through a subclavian or direct aortic route and their data were not included. TIA, Transient ischemic attack; MACCE, major adverse cardiovascular and cerebrovascular events; $N A$, not applicable. *All percentages presented as Kaplan-Meier estimates at the specific point and thus do not equal the number of patients divided by the total number in the study group. †Patients with a pacemaker or implantable cardioverter defibrillator at baseline were included. 
TABLE E5. Major clinical event definitions

Death*

All-cause death

All deaths from any cause after valve intervention (including all cardiovascular and noncardiovascular deaths)

Cardiovascular death

Any death from proximate cardiac cause (eg, MI, cardiac tamponade, worsening heart failure)

Unwitnessed death and death of unknown cause

All procedure-related deaths, including those related to a complication of the procedure or treatment of a complication of the procedure

Death caused by noncoronary vascular conditions (eg, cerebrovascular disease, pulmonary embolism, ruptured aortic aneurysm, dissecting aneurysm, or other vascular disease)

All deaths within $30 \mathrm{~d}$ of procedure

Noncardiovascular death

Any death not covered by the above definitions (eg, death caused by infection, malignancy, sepsis, pulmonary causes, accident, suicide, or trauma)

Valve-related death

Any death caused by prosthetic valve dysfunction, valve thrombosis, embolism, bleeding event, or implanted valve endocarditis

Death related to reintervention on the operated valve

Stroke*

Neurologic events were defined as

Rapid onset of a focal or global neurologic deficit with $\geq 1$ of the following: change in level of consciousness, hemiplegia, hemiparesis, numbness or sensory loss affecting 1 side of the body, dysphasia or aphasia, hemianopia, Amaurosis fugax, or other neurologic signs or symptoms consistent with stroke

Duration of a focal or global neurologic deficit $\geq 24 \mathrm{~h}$; OR $<24 \mathrm{~h}$, if therapeutic interventions were performed (eg, thrombolytic therapy or intracranial angioplasty); OR available neuroimaging studies documenting a new hemorrhage or infarct; OR the neurologic deficit resulted in death

No other readily identifiable nonstroke cause for the clinical presentations (eg, brain tumor, trauma, infection, hypoglycemia, peripheral lesion, pharmacologic influence)*

Confirmation of the diagnosis by $\geq 1$ of the following:

Neurology or neurosurgical specialist

Neuroimaging procedure (MRI or CT or cerebral angiography)

Lumbar puncture (spinal fluid analysis diagnostic of intracranial hemorrhage)

Stroke definitions

Transient ischemia attack

A new focal neurologic deficit with rapid symptom resolution (usually 1-2 h) and always within $24 \mathrm{~h}$

Neuroimaging without tissue injury

Stroke (diagnosed as above, preferably with positive neuroimaging findings)

Minor: modified Rankin $<2$ at 30 and $90 \mathrm{~d}$

Major: modified Rankin $\geq 2$ at 30 and $90 \mathrm{~d} \dagger$

Myocardial infarction*

Periprocedural MI ( $\leq 72 \mathrm{~h}$ after the index procedure)

New ischemic symptoms (eg, chest pain or shortness of breath) or new ischemic signs (eg, ventricular arrhythmias, new or worsening heart failure, new ST-segment changes [elevation $>1 \mathrm{~mm}$ or depression $>1 \mathrm{~mm}$ in $\geq 2$ contiguous leads], hemodynamic instability; or imaging evidence of new loss of viable myocardium or new wall motion abnormality) AND

Elevated cardiac biomarker evidence (preferably creatinine kinase-MB) within $72 \mathrm{~h}$ after the index procedure, consisting of $\geq 2$ postprocedure samples 6-8 $\mathrm{h}$ apart with a $20 \%$ increase in the second sample and a peak value $>10$ times the 99 th percentile URL or a peak value $>5$ times the 99th percentile URL and with new pathologic $\mathrm{Q}$ waves in $\geq 2$ contiguous leads

Spontaneous MI ( $>72 \mathrm{~h}$ after the index procedure), including any of the following

Detection of increase and/or decrease in cardiac biomarkers (preferably troponin) with $\geq 1$ value greater than the 99th percentile URL, together with evidence of myocardial ischemia with $\geq 1$ of the following

ECG changes indicative of new ischemia (new ST-T changes or new LBBB)

New pathologic $Q$ waves in $\geq 2$ contiguous leads

Imaging evidence of new loss of viable myocardium or new regional wall motion abnormality

Sudden, unexpected cardiac death, involving cardiac arrest, often with symptoms suggestive of myocardial ischemia, and accompanied by

presumably new ST elevation, or new LBBB, and/or evidence of fresh thrombus by coronary angiography and/or at autopsy, but death occurring before blood samples could be obtained or before the appearance of cardiac biomarkers in the blood

Pathologic findings of acute MI 


\section{TABLE E5. Continued}

Bleeding events*

Life-threatening or disabling bleeding

Fatal bleeding OR

Bleeding in a critical area or organ (eg, intracranial, intraspinal, intraocular, or pericardial, necessitating pericardiocentesis, or intramuscular with compartment syndrome) OR

Bleeding causing hypovolemic shock or severe hypotension requiring vasopressors or surgery OR

Overt source of bleeding with decrease in hemoglobin of $\geq 5 \mathrm{~g} / \mathrm{dL}$ or whole blood or packed RBC transfusion of $\geq 4 \mathrm{U}$

Major bleeding

Overt bleeding associated with a decrease in hemoglobin level of $\geq 3.0 \mathrm{~g} / \mathrm{dL}$ or requiring transfusion of 2 or $3 \mathrm{U}$ of whole blood RBCs

AND not meeting criteria for life-threatening or disabling bleeding

Major vascular complications*

Any thoracic aortic dissection

Access site or access-related vascular injury (dissection, stenosis, perforation, rupture, arteriovenous fistula, pseudoaneurysm, hematoma, irreversible nerve injury, or compartment syndrome) leading to death, need for significant blood transfusions ( $\geq 4 \mathrm{U}$ ), unplanned percutaneous or surgical intervention, or irreversible end-organ damage (eg, hypogastric artery occlusion causing visceral ischemia or spinal artery injury causing neurologic impairment)

Distal embolization (noncerebral) from a vascular source requiring surgery or resulting in amputation or irreversible end-organ damage

Device success*

Successful vascular access, delivery, and deployment of the device and successful retrieval of the delivery system

Correct position of the device in the proper anatomic location (placement in the annulus with no impedance on device function)

Intended performance of the prosthetic heart valve (aortic valve area $\geq 1.2 \mathrm{~cm}^{2}$ for $26-, 29-$, and $31-\mathrm{mm}$ valves or $\geq 0.9 \mathrm{~cm}{ }^{2}$ for $23-\mathrm{mm}$

valves) and mean aortic valve gradient $<20 \mathrm{~mm} \mathrm{Hg}$ or peak velocity $<3 \mathrm{~m} / \mathrm{s}$ without moderate or severe prosthetic valve aortic

regurgitation

Only 1 valve implanted in the proper anatomic location

$M I$, Myocardial infarction; $M R I$, magnetic resonance imaging; $C T$, computed tomography; $U R L$, upper reference limit; $E C G$, electrocardiographic; $L B B B$, left bundle branch block; $R B C$, red blood cell. *Adapted from Leon and colleagues. ${ }^{17} \dagger$ Discrepancies between the modified Rankin score at $90 \mathrm{~d}$ were adjudicated by the Clinical Events Committee. 